\title{
5 Research Square

\section{Co-implementing Vitamin A supplementation with Seasonal Malaria Chemoprevention in Sokoto State, Nigeria: a feasibility and acceptability study}

Olusola Oresanya ( $\sim$ o.oresanya@malariaconsortium.org)

Malaria Consortium

Abimbola Phillips

Malaria Consortium

Ekechi Okereke

Malaria Consortium

Abraham Ahmadu

Taiwo Ibinaiye

Malaria Consortium

Madeleine Marasciulo-Rice

Malaria Consortium

Charlotte Ward

Malaria Consortium

Olatunde Adesoro

Malaria Consortium

Rilwanu Mohammed

Malaria Consortium

Jamilu Nikau

National Malaria Elimination Programme

Chris Osa Isokpunwu

Malaria Consortium

Mohammad Ali Inname

Sokoto state Ministry of Health

Helen Counihan

Malaria Consortium

Kevin Baker

Malaria Consortium

Kolawole Maxwell

Malaria Consortium

Helen Smith

International Health Consulting Services Ltd 


\section{Research Article}

Keywords: Seasonal malaria chemoprevention, Vitamin A supplementation, Integration, Health campaign effectiveness, Micronutrient deficiency, Intervention coverage, Feasibility, Acceptability, SMC plus vitamin A supplementation

Posted Date: October 13th, 2021

DOl: https://doi.org/10.21203/rs.3.rs-960472/v1

License: (c) (i) This work is licensed under a Creative Commons Attribution 4.0 International License. Read Full License 


\section{Abstract}

\section{Background}

Bi-annual high dose vitamin A supplements administered to children aged 6-59 months can significantly reduce child mortality, but vitamin A supplementation (VAS) coverage is low in Nigeria. The World Health Organization recommends that VAS be integrated into other public health programmes which are aimed at improving child survival. Seasonal malaria chemoprevention (SMC) provides a ready platform for VAS integration to improve health outcomes.

\section{Methods}

A mixed methods study design was used to assess the feasibility and acceptability of co-implementing VAS with SMC in one local government area of Sokoto state in northern Nigeria. Existing SMC implementation tools and job aids were revised and community drug distributors, experienced in SMC delivery, were trained on the determination of VAS eligibility, administration of the correct doses and identification of adverse drug reactions. SMC and VAS were delivered using a door-to-door approach. VAS and SMC coverage were calculated and the outcome of the integration was assessed using questionnaires administered to 188 and 197 households at baseline and endline respectively. The Bowen framework was used to assess feasibility through focus group discussions and key informant interviews; thematic analysis was carried out on the qualitative data.

\section{Results}

At endline, the proportion of children who received at least one dose of VAS in the last six months increased significantly from $2 \%$ to $59 \%(p<0.001)$. There were no adverse effects on the coverage of SMC delivery with $70 \%$ eligible children reached at baseline, increasing to $76 \%(p=0.412)$ at endline. There was no significant change $(p=0.264)$ in the quality of SMC, measured by proportion of children receiving their first dose as directly observed treatment (DOT), at endline (68\%) compared to baseline (54\%). Study findings demonstrated acceptability among caregivers, community drug distributors, State and National healthcare officials.

\section{Conclusion}

This study showed that it is feasible and acceptable to integrate VAS with SMC delivery in areas of high seasonal malaria transmission such as northern Nigeria, where SMC campaigns are implemented. SMCVAS integrated campaign can significantly increase vitamin A coverage but more research is required to demonstrate the feasibility of this integration in different settings and on a larger scale.

\section{Background}

Globally, about two billion people are estimated to have micronutrient deficiencies ${ }^{1}$ and reports indicate that children from low and middle-income countries are most affected. ${ }^{2}$ In Nigeria, vitamin A deficiency is 
a public health problem and a major risk factor for child survival, increasing the number of fatalities caused by common diseases such as acute gastroenteritis and measles. ${ }^{3,4}$ Children with clinical signs of vitamin A deficiency are at least three times more likely to die than children who are not vitamin $\mathrm{A}$ deficient. ${ }^{5}$

High dose vitamin A supplementation (VAS) delivered twice per year to children under five years in low and middle-income countries, is a proven low-cost intervention which has been shown to reduce all-cause mortality by about 24 percent. ${ }^{6,7}$ The World Health Organization (WHO) recommends high dose VAS given every 4 to 6 months to children aged 6-59 months who are at risk of vitamin A deficiency. ${ }^{8}$ Countries with high under-five mortality rates (more than 70 per 1,000 births) and evidence of vitamin $A$ deficiency among this age group have been identified as priority countries for national VAS programmes. ${ }^{9}$ Nigeria, with an under-five mortality rate of 132 per 1000 births $^{10}$, is a priority country for national VAS campaigns. These are conducted bi-annually within the country, mainly during Maternal, Newborn and Child Health (MNCH) weeks, through a health facility-based approach. ${ }^{11}$

According to the 2018 National Nutrition and Health Survey (NNHS), only 41 percent of children aged 6 59 months received VAS in the six months prior to the survey, with Sokoto and four other States recording less than 15 percent coverage. ${ }^{12}$ Between 2014 and 2018, the number of states meeting the minimum threshold of 70 percent coverage at which reductions in child mortality can be expected, reduced from seven to two states in Nigeria. An independent assessment of the $\mathrm{MNCH}$ week revealed that none of the states implemented the strategy as per guidelines and no evidence was found that $\mathrm{MNCH}$ week significantly contributed to coverage of essential MNCH interventions, including VAS. ${ }^{11}$ Addressing the poor VAS coverage among these vulnerable groups is key for child survival in Nigeria and critical for universal health coverage. To promote more equitable access to this life-saving intervention, WHO recommends that VAS be integrated into other public health programmes which are aimed at improving child survival, ${ }^{8}$ as evidence suggests that integrating interventions for multiple diseases can increase coverage, improve health outcomes and could be cost-effective. ${ }^{13,14,15}$

Seasonal malaria chemoprevention (SMC) provides a ready and viable platform to integrate VAS for higher coverage for children under five years old. SMC involves four-monthly administration of three-day treatment courses of sulfadoxine-pyrimethamine (SP) and amodiaquine (AQ), also called SPAQ, to children 3-59 months. This is where malaria transmission is highly seasonal, usually between July and October, in the Sahel region of sub-Saharan Africa. ${ }^{16}$ The goal is to maintain therapeutic antimalarial drug concentrations in the blood throughout the period of greatest risk to prevent malaria. ${ }^{17}$ The SMC intervention has been successfully implemented with coverage of more than 80 percent in Sokoto, Zamfara, Katsina, Jigawa, Kebbi and Yobe states with good acceptability. ${ }^{18}$ In Nigeria, SMC is delivered during each cycle using a door-to-door approach, where teams of community health workers called community drug distributors (CDDs) visit each household within their assigned catchment areas to administer the first dose of SPAQ as a directly observed treatment (DOT), and provide information to caregivers on how to administer the remaining two subsequent daily doses of AQ. 
The SMC platform has been used to increase vaccination rates in children under five by over 50 percent in Mali. ${ }^{19}$ A study within northern Nigeria reported that when a lipid-based nutrient supplement (LNS) distribution was integrated with SMC programme, coverage for the LNS was about 85 percent, without any significant effect on SMC coverage, which was also high at 90 percent. ${ }^{20} \mathrm{SMC}$ uses a door-to-door delivery strategy, giving more children missed by the outreach strategy implemented during the VAS campaigns the opportunity to be reached to receive at least one dose during the year.

Despite the potential benefits of co-implementing VAS with SMC, there are some challenges that need to be addressed. Firstly, the safety of administering VAS via the SMC platform that is designed to target a different age group is a key concern. While SMC targets children aged 3-59 months, VAS is administered to children aged 6-59 months, there is thus the challenge for CDDs to determine which children are eligible for both vitamin A capsules and SPAQ. A second concern is that the interval between treatments with vitamin A capsules and SPAQ varies. VAS should be administered once every four to six months while SMC is given over a three-day period monthly over four consecutive months. In Nigeria, VAS campaigns are carried out in May/June and October/November whereas SMC administration typically happens from July to October each year. This timing shows an overlap only in October, therefore making integration possible only once a year. Thirdly, an integrated strategy will require that CDDs acquire additional skills to administer vitamin A capsules, perform additional tasks, and spend more time to complete the household visit, all of which could result in extra workload and possibly compromise the coverage of SMC or the quality of delivery. While the existing SMC programme in Nigeria provides a ready platform and an opportunity to do more with available resources, concerns remain about overloading the CDDs and their work being less effective. ${ }^{21,22}$ Furthermore, the feasibility and acceptability among caregivers and CDDs of integrating VAS with SMC, is unknown.

Malaria Consortium in collaboration with the National Malaria Elimination Programme (NMEP) in Nigeria, Sokoto state Malaria Elimination Agency and Sokoto state Primary Healthcare Board, carried out a study to understand the feasibility and acceptability of co-implementing VAS with SMC delivery, using one local government area (LGA) in Sokoto state. Its objectives were to assess the feasibility of integrating VAS with the SMC programme, explore the acceptability of integration from the perspectives of CDDs, caregivers, state and national-level healthcare programme officers; and estimate potential changes to the coverage and quality of SMC after integration. This pilot implementation study was undertaken to provide evidence for the possible scale-up of the integration as well as to guide future implementation, which will potentially increase VAS coverage within Nigeria.

\section{Methods}

\section{Study setting and population}

Sokoto state is in north-western Nigeria and SMC is currently implemented in all 23 LGAs of the state. Child health indices in the state are poor; the 2018 Nigeria Demographic and Health Survey (NDHS) indicates that only 5 percent of $6-59$-month-old children received all age-appropriate vaccinations. ${ }^{10}$ The 
proportion of eligible children who received at least one dose of VAS six months prior to the NNHS was estimated at 6.2 percent. $^{12}$

This study was conducted in Dange-Shuni LGA, located in the south-eastern part of Sokoto state. Based on projections from the 2006 national census report, Dange-Shuni with its eleven wards has a total estimated population of 285,697 and under-five population of approximately $57,139 .{ }^{23}$ SMC commenced in Dange-Shuni LGA in 2016 and coverage in 2018 was 100 percent. $^{18}$

The study population was children aged 6-59 months eligible for SMC and VAS who reside in Dange Shuni LGA. Children who fell outside this age range, those who have suffered from severe illness or allergies or had taken VAS in the month prior to the commencement of the study were excluded from this pilot implementation study.

\section{Study design, sample size and sampling procedure}

The study used mixed methods, with baseline and endline comparisons of VAS and SMC coverage along with focus group discussions (FGDs) and key informant interviews (KIIs). To provide estimates for VAS and SMC coverage both at baseline and at endline, the study required a minimum sample of 180 eligible under-five children. The sample size was obtained by using one-sample proportion formula, assuming a proportion of 6.2 percent [which represents the proportion of eligible children who received at least one dose of vitamin A six months prior to the NNHS in Sokoto state] at the 95 percent confidence level $(\mathrm{Cl})$, and allowing for a design effect of two with 30 clusters. The sampling procedure involved the selection of an eligible child from each of six randomly selected households from each of three randomly selected communities within each ward. A total of 198 households were to be sampled for interviews from 33 communities in all 11 wards at baseline and endline from the same catchment communities of focal health facilities in Dange Shuni LGA.

\section{Adaptation of tools, quality assurance and study implementation}

The pilot study leveraged on existing standard tools used for documenting VAS and SMC data separately. SMC tally sheets and referral forms were adapted to capture the required indicators for vitamin $A$ monitoring and commodity tracking; tools for both interventions were combined. A supply-chainmanagement system for both drugs was set up with all the required resources and materials. CDD teams were attached to health facilities for commodity logistics and submission of reports. A designated health worker within each facility provided supportive supervision to the CDD teams attached to each health facility.

There was a training of trainers on the protocol for the integration of SMC with VAS at the state level facilitated by resource persons from the Nutrition Unit of the Federal Ministry of Health and NMEP. Subsequently CDDs and their supervisors were trained by the state trainers, using a revised training guide and job-aids. Guidelines were developed to help the CDDs determine the age of children to ensure vitamin A was administered to children aged 6-11 months and 12-59 months at the age-appropriate dose. The 
training focused on how to assess eligibility, how to administer VAS along with SPAQ, identification of adverse drug events and how to record data. Quality assurance for the training was ensured through administration of pre- and post-tests and competency assessment.

VAS was implemented during the last month (cycle 4) of SMC delivery i.e. October 2019. The CDDs followed the same standard operating procedure for SMC with additional steps to administer vitamin $A$ capsules to 6-59-month-old children. CDDs worked in pairs, one CDD administering SPAQ and vitamin A, while the other counted and recorded treatments in the SMC tally sheet and other tools such as the Child Health card and Child SMC card. In order to accommodate the extra workload, the daily target of the CDDs was reduced from 70 children per day to 60 children per day and more CDDs were recruited. State and LGA teams monitored activities at the health facility and in the community using standard checklists.

\section{Data collection and analysis}

\section{Quantitative data}

Trained data collectors interviewed household heads and caregivers of eligible children who were sampled at baseline and then at endline using structured questionnaires uploaded on mobile android devices. Data were collected on knowledge of VAS and SMC, children receiving SMC and/or VAS and those receiving the first dose of SMC as DOT, among others. Baseline VAS coverage was estimated according to the proportion of eligible children who had received VAS during the MNCH week or a related intervention (such as National Immunization Plus days) in the six months preceding the study. Baseline SMC coverage refers to the proportion of eligible children who had received at least the first dose of SMC during the third cycle of the 2019 SMC campaign. Endline refers to coverage achieved through the coimplementation of VAS with SMC during the fourth cycle of the SMC campaign.

Frequencies and proportions were calculated for the quantitative data using STATA 15. Coverage points estimates with 95 percent Cls were calculated and compared between survey periods using clusteradjusted chi-square tests. ${ }^{24}$

\section{Qualitative data}

Topic guides for the key informant interviews were developed based on a framework developed by Bowen et al to measure important aspects of feasibility. ${ }^{25}$ Topic guides for FGDs were developed using a comprehensive framework for acceptability of healthcare interventions. ${ }^{26}$ Pre-testing of the FGD guide was first conducted prior to qualitative data collection through 12 FGDs, which were conducted with caregivers, CDDs and the supervisors of CDDs. Male and female respondents participated in separate FGDs to allow for independence in the expression of perceptions, avoiding bias by perceived gender roles. In addition, 12 key informants' interviews were conducted with officials from the Federal Ministry of Health, State Ministry of Health and LGA Health department in addition to donors and technical partners. Only those who participated in the planning, implementation or supervision of SMC in 2019 were identified for interviews. Qualitative data were collected about 2-3 weeks after the fourth SMC cycle. Data 
collectors transcribed the qualitative data from audio recordings and the notes taken during the interview. Thematic analysis was carried out using MAXQDA software to identify important themes and constructs based on participants' perceptions.

\section{Ethical considerations}

Ethical approval was obtained in September 2019 from the research ethics committee of the Sokoto state Ministry of Health (SMHOH/DHPRS/1830/VOL1) and from the Liverpool School of Tropical Medicine Research Ethics Committee (reference number: 19-075). Written informed consent was sought and obtained from each study respondent prior to commencing interviews and study participants were assured of the confidentiality of their responses.

\section{Results}

\section{Quantitative Results}

During fieldwork, a total of 188 and 197 caregivers of eligible children were interviewed at baseline and endline respectively, from the 198 sampled households for the quantitative component of the study. This represents a response rate of 94.9 percent at baseline and 99.5 percent at endline.

\section{Key characteristics of caregivers for the selected eligible children}

Almost all the caregivers of the selected children were females, married (98 percent) and mostly unemployed. The majority of the caregivers who were interviewed at baseline ( 89 percent) and at endline (88 percent) had never attended school.

\section{Table 1 - Demographic characteristics of caregivers at baseline and endline}


Variable

Baseline

Endline

\begin{tabular}{lcl} 
& $N=188$ & $N=197$ \\
& $\mathrm{n}(\%)$ & $\mathrm{N}(\%)$ \\
\hline Mean Age (Std. Deviation) & $29.5(7.0)$ & $28.0(6.8)$ \\
\hline Sex & & \\
\hline Male & $3(1.6)$ & $2(1.0)$ \\
\hline Female & $185(98.4)$ & $195(99.0)$ \\
\hline & & \\
\hline Marital status & & $193(98.0)$ \\
\hline Married & $185(98.4)$ & $1(0.5)$ \\
\hline Single & $1(0.5)$ & $3(1.5)$ \\
\hline Widowed & $2(1.1)$ & \\
\hline
\end{tabular}

\section{Occupation}

\begin{tabular}{lll} 
Farming & $1(0.5)$ & $3(1.5)$ \\
\hline Teaching & $1(0.5)$ & $1(0.5)$ \\
\hline Trading & $49(26.1)$ & $87(44.2)$ \\
\hline Other & $6(3.2)$ & $10(5.1)$ \\
\hline Unemployed & \multicolumn{1}{c}{$131(69.7)$} & $96(48.7)$
\end{tabular}

\section{Ever attended school}

\begin{tabular}{lrr}
\hline No & $167(88.8)$ & $174(88.3)$ \\
\hline Yes & $21(11.2)$ & $23(11.7)$ \\
\hline
\end{tabular}

Relationship with selected child

Mother

181 (96.3)

193 (98.0)

Others

7 (1.1)

4 (1.5) 
Awareness of vitamin A and seasonal malaria chemoprevention

Caregivers' awareness of vitamin A (those who have ever heard of vitamin A) was low at baseline (10 percent) but significantly increased at endline to 62 percent $(p<0.001)$ after the integration of VAS with the SMC campaign. Awareness of MNCH week was very low (4 percent) at baseline increasing to 19 percent at endline. Awareness of SMC was very high at both baseline (91 percent) and endline (97 percent) (Table 2).

Table 2: Caregivers' level of awareness of vitamin A supplementation and seasonal malaria chemoprevention

$\begin{array}{cccc}\text { Variable } & \text { Baseline } & \text { Endline } & \chi^{2} \text { (P-value) } \\ & N=188(\%) & N=197 & \end{array}$

(\%)

\begin{tabular}{lcccc}
\hline Awareness of vitamin A & $10 \%$ & $62 \%$ & $113.16(\mathrm{p}<0.001)$ \\
\hline Awareness of SMC & $91 \%$ & $97 \%$ & $5.57(\mathrm{p}=0.061)$ \\
\hline Awareness of MNCH week & $4 \%$ & $19 \%$ & $26.78(\mathrm{p}=0.021)$
\end{tabular}

There was an equal distribution of male and female children at both baseline and endline and most children at baseline and endline were aged 24-59 months. (Table 3).

Table 3 - Key characteristics of selected children at baseline and endline 


\begin{tabular}{|c|c|c|c|}
\hline Variable & $\begin{array}{c}\text { Baseline } \\
\mathrm{N}=188 \text { (percent) }\end{array}$ & $\begin{array}{c}\text { Endline } \\
\mathrm{N}=197 \text { (percent) }\end{array}$ & $\chi^{2}$ (P-value) \\
\hline \multicolumn{4}{|l|}{ Sex } \\
\hline Male & $94(50.0)$ & $100(50.8)$ & \multirow[t]{2}{*}{$0.02(0.843)$} \\
\hline Female & $94(50.0)$ & $97(49.2)$ & \\
\hline \multicolumn{4}{|c|}{ Age of child (months) } \\
\hline $6-11$ & $19(10.1)$ & $13(6.6)$ & \multirow{3}{*}{$1.84(0.160)$} \\
\hline $12-23$ & $38(20.2)$ & $37(18.8)$ & \\
\hline $24-59$ & 131 (69.7) & 147 (74.6) & \\
\hline
\end{tabular}

Coverage of vitamin A supplementation and seasonal malaria chemoprevention

Coverage of VAS at baseline was low (2 percent; 95 percent $\mathrm{Cl}=0.4-7.0)$ and increased at endline (59 percent; 95 percent $\mathrm{Cl}=47.0-70.7 ; \mathrm{p}=0.001$ ) (Table 4).

Table 4 - Comparison of Vitamin A and SMC Coverage between baseline and endline surveys

\begin{tabular}{|c|c|c|c|}
\hline Characteristic & $\begin{array}{l}\text { Baseline } \\
N=188\end{array}$ & $\begin{array}{l}\text { Endline } \\
\mathrm{N}=197\end{array}$ & $\begin{array}{l}\square^{2} \\
\text { (p-value) }\end{array}$ \\
\hline Child received vitamin A supplement & $\mathrm{n}$ (percent) & $\mathrm{n}$ (percent) & \multirow[t]{3}{*}{$87.71(p<0.001)$} \\
\hline Yes & $3(1.6)$ & $117(59.4)$ & \\
\hline No & $185(98.4)$ & $80(40.6)$ & \\
\hline Child received SPAQ for SMC & $\mathrm{n}$ (percent) & n (percent) & \multirow{3}{*}{$0.68(0.4)$} \\
\hline Yes & $131(69.7)$ & $149(75.6)$ & \\
\hline No & $57(30.3)$ & $48(24.4)$ & \\
\hline
\end{tabular}


For children who did not receive vitamin A, the most common reason given by caregivers at both baseline and endline was that the CDD did not visit the house. However, this reason was given more frequently at baseline (62 percent) compared to endline (49 percent) (Figure 1). SMC coverage increased slightly from 70 percent (95 percent Cl: $57-80$ percent) at baseline to 76 percent (95 percent Cl: $65-84$ percent) at endline $(p=0.4)$ (Table 4). Similarly, the most common reason given for not receiving SMC by caregivers was that a CDD did not visit the household. Figure 2 shows that this reason was more frequent at baseline (83 percent) compared to endline (67 percent).

\section{Figure 1: Reasons for child not receiving vitamin A (percent)}

\section{Figure 2: Reasons for child not receiving SMC}

\section{Adherence to seasonal malaria chemoprevention dosage regimen at baseline and endline}

Administration of the first dose of SMC by CDDs through DOT was lower at endline compared to baseline (54 percent vs 68 percent), however this difference was not statistically significant $(p=0.264)$. The administration of the second and third doses for SMC by the caregiver were similar at both baseline and endline (Table 5). Among children who received SMC, 11 out of 131 (8 percent) and 18 out of 149 (12 percent) reported having side-effects at baseline and endline respectively. The most common side-effects reported were vomiting and fever during both the baseline and endline surveys.

Table 5 - Adherence to seasonal malaria chemoprevention dosage regimen with SPAQ at baseline and endline

\begin{tabular}{|c|c|c|c|}
\hline Variable & $\begin{array}{l}\text { Baseline } \\
n=131 \\
(\%)\end{array}$ & $\begin{array}{l}\text { Endline } \\
n=149 \\
(\%)\end{array}$ & $\begin{array}{l}p- \\
\text { value }\end{array}$ \\
\hline & $95 \% \mathrm{Cl}$ & $95 \% \mathrm{Cl}$ & \\
\hline$D D$ on $1^{\text {st }}$ day via & $86(67.5)$ & $80(53.7)$ & 0.264 \\
\hline nd day & $126(96.2)$ & 149 (98.0) & 0.380 \\
\hline d day & $126(96.2)$ & $142(95.3)$ & 0.739 \\
\hline
\end{tabular}

\section{Qualitative results}

Feasibility 
The key sub-themes identified under feasibility include factors facilitating implementation of the integrated programme; barriers to implementation of the integrated programme; and sustainability of the integrated programme.

\section{Factors facilitating implementation of the integrated programme}

Most national and state health officials felt that because the administration of VAS does not require technical knowledge, this makes it easy for anyone to easily undertake the work, thus facilitating its integration with SMC.

"It does not require someone who went to school of Nursing or School of Health Technology to do the work....." (State level health official, Sokoto state)

Key informants mentioned that the SMC platform, with committed CDDs along with its established procurement processes, has facilitated effective integration with VAS. They argued that VAS should easily be absorbed into the SMC supply chain.

"They (community drug distributors) have the passion to serve their people that is why they agreed to take the challenge..." (State level health official, Sokoto state)

"... we believe that the procurers of the SMC commodities should be able to support sourcing vitamin A in the long run." (National level key informant, Abuja)

Another factor which has facilitated the integration of VAS with SMC are the trainings which were given to the CDDs and their supervisors. During trainings, eligibility criteria were emphasized, grey areas were clarified and the benefits of an integrated programme were discussed.

"When I first heard about this integration, I thought it would be difficult, administering two drugs at the same time, but with the good training, I can do it easily' (Female community drug distributor, DangeShuni LGA)

The majority of CDDs and their supervisors reiterated the importance of community and religious leaders [imams] and town announcers in engaging with, as well as raising awareness among, community members about the integrated programme. However, some feedback received was that radio announcements about the addition of VAS to the SMC campaigns were insufficient. Community and religious leaders should be more involved in sensitization and information-sharing within the community prior to future campaigns.

"...to improve it based on the information we heard, is mobilization through community leaders, District Heads and Imams as well as town announcers for caregivers to cooperate... "(Supervisor of community drug distributors, Dange-Shuni LGA)

\section{Barriers to implementation of the integrated programme}


Reliable data collection was an area of concern for key informants. A recommendation to address this concern was the harmonization of data collection tools used for the programme with existing health management information system tools, for example by introducing one tool to capture all immunization, SMC and VAS administration.

The potential for confusion, which could arise when administering VAS and SMC to different age groups was another key challenge raised by study respondents; especially since different age groups receive different dosing regimens of the drugs based on their age. There were also concerns expressed by caregivers that taking two drugs at the same time might be too much for their children. Key informants reiterated the need for proper monitoring to prevent the possibility of overdose particularly among younger children.

"...some caregivers still feel it's too much for a child to receive SMC and vitamin A together at the same time..." (Female community drug distributor, Dange-Shuni LGA)

Key informants highlighted the need to further deliberate and then harmonize the timings for SMC-VAS administration.

Some caregivers and key informants felt that the performance of the CDDs was affected because of the integration of VAS with SMC. There were reports by caregivers that some CDDs were not patient enough to wait 30 minutes, which is required between the administration of SMC and VAS as well as to see if the child vomits. Others mentioned that some CDDs 'gave the drugs at the same time'. Some study respondents complained that 'some community drug distributors did not wait for children to return home' when absent, while others 'only asked the number of children in the household, gave out VAS and SMC and then filled the tally cards' - these are against the guidelines provided during trainings.

"...the timing is something that I know will be a problem because we know the attitude of our health workers, it is unlikely for them to wait that 30 minutes..." (State healthcare official, Sokoto state)

Study respondents mentioned that the integration was time-consuming, such that most CDDs were unable to meet their targets due to the additional workload, also resulting in far more time spent in the field during the campaign.

"We wasted a lot of time. During SMC activities we close at 2 or 3pm, but with the addition of VAS we are sometimes in the field until 6pm." (Male community drug distributor, Dange-Shuni LGA)

"...operationally that is what is recommended for them - to wait for like 30 minutes after giving the SMC drugs, but in practice this hardly happens, because if they are to wait 30 minutes in every house they may end up visiting only few households..." (National level key informant, Abuja)

A few supervisors indicated that some CDDs reported being stressed, unhappy and complained about the excessive workload and the need to wait. Caregivers and the supervisors of CDDs suggested that separate teams should be employed to administer SMC on a day different from the day the VAS is 
administered. Some key informants recommended reducing the daily targets or increasing the number of CDD teams.

Another major concern raised by study respondents was remuneration for the CDDs and supervisors. There were complaints of 'no increase in remuneration', delays in payments or sometimes no payments received at all, despite the additional workload. These circumstances gave rise to comments that CDDs as well as some supervisors may not participate or 'give their best' in future campaigns, if the issues with their remuneration were not resolved.

"When we heard about the addition of VAS to SMC, we thought payment would be increased..." (Female community drug distributor, Dange-Shuni LGA)

The difficulties in deploying materials and medications to hard-to-reach communities (thereby avoiding stock-outs) plus the potential difficulties in securing adequate budgetary allocation to deliver the integrated programme by states were additional challenges identified, which could affect the feasibility and sustainability of the programme.

\section{Sustainability of the integrated programme}

Most study respondents indicated that the sustainability of the integrated programme is largely dependent on continuous sensitization and mobilization within communities, particularly with the help of community and religious leaders. They argued that this will increase support for the programme, help to convince caregivers who may have misconceptions about the programme, in addition to ensuring that the complete dose of VAS and SMC are administered to eligible children under five years old.

"...creating awareness is the key to success in this programme, there is the need to mobilize and sensitize people in the community." (Female caregiver, Dange-Shuni LGA)

Some supervisors and key informants advised that selecting CDDs from communities in which they will be employed to distribute drugs is crucial for successful implementation and community acceptability. CDDs will be motivated to provide value to their own communities and will better understand the terrain where they will be working than if they were not from the community. Key informants argued that implementers should 'employ more females than males' as females tend to have easier access to households within communities in northern Nigeria than males due to cultural norms.

"... on the recruitment of workers. If you consider the people of hard-to-reach areas and you pick people from such areas, they will have more confidence to do the work and the community members will cooperate." (Supervisor of community drug distributors, Dange-Shuni LGA)

Key informants, supervisors and the CDDs emphasized that the programme's continuity will depend on stakeholders at different levels of the health system being involved from the start and then actively playing their roles to support the integrated programme. State governments should claim ownership of the integrated programme and provide the governance and accountability structures as well as the 
budgetary allocations required for successful implementation and sustainability. Community-level governance, stewardship and accountability are also important for sustainability and this could be facilitated via the effective functioning and active participation of ward development committees (WDCs). There were also suggestions about exploring alternative funding sources, including publicprivate partnerships and corporate social responsibility funds, instead of depending on foreign donors.

"...sustainability has to start from government. Government must take ownership..." (National level key informant, Abuja)

\section{Acceptability}

The key sub-themes identified under acceptability were positive view and good reception of the integrated SMC-VAS programme; no adverse events and infrequent side effects; viewed as an innovation for improving access to life-saving medications, and demand to widen eligibility.

\section{Positive view and good reception of the integrated SMC-VAS programme}

The level of acceptability about the integration of VAS with SMC among all respondents was high. Caregivers felt "that it is a very good and welcome development" and liked the convenience of CDDs going door-to-door within communities to give the drugs. They expressed their support for the scale-up of the integrated programme and reported that "with the intervention, the children are getting healthier".

"I heard nothing except appreciation about the development brought by the government to fight malaria and malnutrition among children..." (Male caregiver, Dange-Shuni LGA)

CDDs highlighted the benefits of administering VAS and SMC together and indicated that caregivers are more receptive to the integrated programme because of the perceived health benefits and the communitybased door-to-door delivery approach.

“...it's really important because it's like helping a child in two different aspects, preventing him from malaria and at the same time boosting the child's immune system and brain function..." (Female community drug distributor, Dange-Shuni LGA)

Key informants also commented on the efficiency and potentially higher impact of integrating VAS with SMC.

"... we believe that one of the major problems that we are having in primary health care is lack of integration of activities; when you have one, two, three interventions for the same age group, why not integrate it and have a better coverage than doing separate programs..." (State health official, Sokoto state).

Caregivers reported that they are willing to support and recommend the integration of VAS with SMC. Most eligible children received both drugs, except where a child or their caregiver was absent. The majority of households welcomed the CDDs and accepted the medications. However, some existing 
norms within communities that healthy people do not take medications may give rise to some rejections, reiterating the need for community members to be properly informed by CDDs, healthcare officials as well as religious and community leaders.

"The community drug distributor should explain to the caregivers the benefits of the drugs in each household they enter before administration of the drugs..." (Male caregiver, Dange-Shuni LGA)

Many study respondents felt that acceptability is predicated on awareness among caregivers of the health benefits of both medications. National and State healthcare officials suggested that high acceptance may be due to the popularity of vitamin A and the knowledge of its health benefits among many caregivers, who previously had to go to health facilities to receive the medication but now it is given to households directly. Households in hard-to-reach communities were especially happy that medications were brought to their homes.

"...before we suffer when our children are ill and have to go to the health facility, but now the drugs are brought to the comfort of our homes..." (Female caregiver, Dange-Shuni LGA)

Some study respondents indicated that acceptance of the integrated programme will likely improve if mosquito nets are distributed within the community during the campaigns as part of an integrated package of interventions.

"...you go into houses and they ask you for mosquito net because some of them are pregnant and they need it." (Female caregiver, Dange-Shuni LGA).

\section{No adverse events and infrequent side effects}

Study respondents reported no severe adverse events from the co-implementation of VAS and SMC. Caregivers indicated that some children vomited, while others had fever, loss of appetite and weakness after taking the medications, especially the anti-malaria drugs. However, these were not seen as unusual since children typically experience such symptoms when they are vaccinated and any side-effects were quickly relieved within a day after the drugs were administered.

"...sometimes it causes lack of energy, fever and loss of appetite, but all of these symptoms happen that same day when they take the medication. By the next day, they become fine..." (Female caregiver, Dange-Shuni LGA)

\section{Viewed as an innovation for improving access to life-saving medications}

National and state healthcare officials viewed the integration as an innovation that will improve access to life-saving medications and thus were supportive of the programme's scale up. It was indicated that children from households in hard-to-reach communities who previously did not receive, or experienced difficulties in accessing these interventions were now covered. As a result, they felt that caregivers within 
the intervention communities will not have to wait for $\mathrm{MNCH}$ weeks or visits to health facilities to access these life-saving medications.

"... we thought it was very innovative, this is the first time we are considering this kind of implementation for vitamin A and malaria interventions to the same beneficiaries [under-fives]" (National level key informant, Abuja)

\section{Demand to widen eligibility}

Another factor indicating acceptability for the integration of VAS and SMC is the request from caregivers to widen the eligibility criteria to include children over five years old as well as adults. They argued that since vitamin A improves children's sight, then it should be beneficial for older children and adults as well.

"They should bring more drugs even for those children that are above 5 years...and even for adults, because we also need it" (Female caregiver, Dange-Shuni LGA).

\section{Discussion}

This study was designed to assess the feasibility and explore the acceptability of integrating VAS with SMC, through a pilot intervention in one LGA in Sokoto state within northern Nigeria. The increased coverage of VAS from 2 percent at baseline to 59 percent at endline suggests that an integrated SMC-VAS program provides a feasible platform to increase coverage of VAS for children under five years. This finding is similar to the result from a pilot conducted in Mali, where integration of vaccination with SMC delivery increased vaccination coverage. ${ }^{19}$ This integration had no negative impact on SMC delivery, in line with findings from a similar SMC integration study in Nigeria. ${ }^{20}$

Interestingly, the study also showed that SPAQ coverage marginally increased from 70 percent at baseline to 76 percent at endline following the integration of VAS with SMC. Caregivers were less likely to report that CDDs did not visit their households as a reason for children not receiving SPAQ, when VAS was integrated with SMC at endline than at baseline (67 percent vs 83 percent). Although these results were not statistically significant, exploration during FGDs and KIls indicated that integration was viewed positively, had good reception and is acceptable at community level. These findings strengthen the argument for delivering key life-saving interventions ${ }^{27}$ through integrated programmes, which helps to stretch available resources to deliver more dividends, especially in resource-poor setting such as subSaharan Africa. ${ }^{13,14.15}$ These findings however warrant further investigations in future studies on SMCVAS integration.

One of the fears of integrating interventions or health service delivery is a compromise on quality of delivery following integration. This has been adduced to low adherence to quality guidelines due to limited time or extra workload. ${ }^{28}$ However it has been established that $\mathrm{CHWs}$ can deliver quality services with adequate supervision, motivation and supplies. ${ }^{16}$ The study did not show a significant difference 
between the percentage of children who received the first dose of SMC as DOT at baseline compared to endline following the integration (68 percent vs 54 percent). This implies the integration did not adversely affect the quality of delivery of SMC.

While some studies have shown that $\mathrm{CHWs}$ could take on some extra tasks without this necessarily affecting their quality-of-service delivery; ${ }^{31,32}$ others have reiterated the direct relationship between work overload and overall productivity and effectiveness of $\mathrm{CHWs} .{ }^{33,34}$ During the FGDs, some CDDs complained about waiting time between administration of SPAQ and Vitamin A, and spending more time because of the integration, but this did not adversely affect their output on quality in this study. The debate about what should constitute an appropriate workload for a CDD is a long-standing one. Although there are worries on one hand about not overloading them, on the other hand, concerns remain that CHWs' work is less effective than it could be ${ }^{29}$ and there are 'missed-opportunities'. ${ }^{30}$ CDD's time management and efficiency while in the field is an issue worth exploring in future studies to inform scale up of the integrated campaign. Oliver et al ${ }^{35}$ agreed that there is no question of whether $\mathrm{CHWs}$ can be key agents in improving health; the question lies in how to maximize their potential and do more with existing resources.

Acceptability among caregivers in this study was quite high, but acceptability of the integrated campaign could be affected by cultural norms and traditional beliefs. Lack of sensitivity to gender roles and biases when selecting CDDs could affect programme acceptability within communities, as households are likely more willing to allow female CDDs than male CDDs to enter their homes to administer the drugs because of cultural norms, especially in northern Nigeria. These should be addressed through appropriate community sensitization and mobilization as well as through targeted social and behaviour change communication messages. ${ }^{36,37}$ A key motivating factor for community health workers identified at organizational level by Greenspan et al, ${ }^{38}$ amongst others, is stipend or remuneration. This study revealed dissatisfaction of the CDDs with the remuneration and the lack of promptness in paying it. It is important to determine the best remuneration packages within available resources as well as institute prompt payment mechanisms when planning for scale up to mitigate demotivation of the CDDs and ensure quality delivery of the integrated intervention.

This study also identified key success factors for an integrated SMC and VAS campaign, which include a seamless integration of data collection and field monitoring tools, adequate training of health workers and CDDs, supportive supervision, strong pharmacovigilance systems, as well as a strong coordination between key stakeholders and programme implementers at all levels during planning and delivery of the intervention. Coordination is particularly important given that the two interventions (SMC and VAS) are typically domiciled in different units of the health system - malaria programme and child health programme respectively. According to WHO, programme integration calls for a comprehensive approach with greater emphasis on prevention and the effective management of diseases as well as coordination of care using multidisciplinary teams. ${ }^{39}$ 
Ultimately, sustainability and scale-up of implementation will depend on ownership by governments at different levels and their commitment to provide human as well as financial resources to support this initiative. Some key informants argued that funding support to the government could be provided through public-private partnerships and corporate social responsibility initiatives; however, this will require effective coordination and proper ring fencing of funds to be successful. Community governance structures such as the WDCs are also required to foster accountability, promote acceptability and improve ownership of the integrated programme. ${ }^{40}$

This study is the first to investigate feasibility of integration of high dose VAS with a proven malaria intervention such as SMC. Previous VAS integration programmes were based on immunization campaigns. ${ }^{41,42}$ Another study integrated VAS with a deworming campaign in Kenya and reported a lower coverage for VAS. ${ }^{43}$ The significant increase in VAS coverage demonstrated by this pilot authenticates the viability of the SMC platform to deliver VAS and potentially reach more children that are vulnerable. In 2020, over 12 million children under 5 years were reached with SMC in northern Nigeria, ${ }^{44}$ an area also known to have poor coverage of VAS. ${ }^{12}$

\section{Study Limitations}

It is important to bear in mind some limitations while interpreting the results of this study. Some key informants targeted were unavailable, while others involved in the study had not much knowledge of the integrated SMC-VAS programme, thereby providing limited information and feedback. Another limitation is that due to the changing security situation in the project area, the same households were not visited at endline as those sampled at baseline. Some differences in background characteristics of study participants between baseline and endline may have contributed to the differences in VAS coverage, the direction of which could not be ascertained, as there was no information about those that did not participate in the study. However, since most households in the same localities are similar, this is not likely to have affected the study in a significant way.

\section{Conclusion}

This study has demonstrated the feasibility and acceptability of co-implementing SMC with VAS. It has provided evidence that vitamin A coverage can be significantly increased when integrated with SMC campaigns without negatively affecting the quality of delivery or decreasing the coverage of SMC. SMC platform could be used as a complementary platform to $\mathrm{MNCH}$ weeks for delivering at least one dose of VAS to eligible children annually with higher coverage. However, scaling up co-implementation will require a validation of the findings of this study on a larger scale; testing in varied contexts to tackle other potential barriers; evaluation of cost-effectiveness to inform scale-up and addressing issues identified in the study that could jeopardize future implementation.

\section{Declarations}




\section{Ethics approval and consent to participate}

The study protocol received ethical approval from the ethics committee of the Sokoto State Ministry of Health, Sokoto state, Nigeria and from the Liverpool School of Tropical Medicine Research Ethics Committee. Written informed consent was sought and obtained from each study respondent prior to starting the interviews for the study.

Consent for publication: Not Applicable

\section{Availability of data and materials}

The datasets for this study are available from the corresponding author upon reasonable request.

\section{Competing interests}

The authors completed the Unified Competing Interest form at www.icmje.org/coi_disclosure.pdf (available upon request from the corresponding author), and all authors declare that they have no competing interests.

\section{Funding}

This research was carried out as part of Malaria Consortium's SMC Project. Malaria Consortium's SMC Project is funded through the Open Philanthropy Project Fund, a donor advised fund of Silicon Valley Community Foundation and from individual donors. Vitamin Angels donated the vitamin A capsules used for the study. The funding bodies and donors for this study had no role in the design of the study, the collection, analysis and interpretation of data or writing of the manuscript.

\section{Authors' contributions:}

OO: Corresponding author/Principal Investigator for the study, conceptualization of the study, developed study protocol, coordinated the adaptation and revision of tools for the study, coordinated and facilitated training of project implementers and research assistants, contributed to the critical revision for intellectual content and finalization of the manuscript. AP: Coordinated training on the qualitative aspect of the research, data analysis, interpretation, report writing and contributed to drafting of the manuscript. EO: Developed first draft of the paper from an existing report, contributed to data analysis and coordinated manuscript review. AA: Co-PI for the study, conceptualization of the study, contributed to protocol development, revision of tools for the study and led the data collection process for the study. Tl: Contributed data acquisition, data analysis and interpretation and manuscript review. RM: Contributed to study design, training of personnel, field administration and review of draft manuscript. MM: Led the adaptation of tools for the study and contributed to critically revising the manuscript for important intellectual content. CW: Contributed to conceptualization of the study, reviewed protocol as well as the draft manuscript. TO, JN, MAI and KB: Co-PI for the study, conceptualization of the study, supported trainings and provided program support for the study. HC: Facilitated the qualitative evaluation of the 
study/manuscript review \& editing/consent to final version of manuscript. KM: Programme management/Manuscript review \& editing/ Consent to final version of manuscript. HS: Contributed to conceptualization of the study, protocol review, facilitation of the qualitative evaluation of the study and led the qualitative data analysis for the study.

\section{Acknowledgement}

The authors acknowledge Malaria Consortium's Global SMC Project Director, Christian Rassi, for approving fund release for the research and Dr. Nnenna Ogbulafor, the Head of Case management branch NMEP, for her support in stakeholder engagement. We are grateful to and thank Sol Richardson, Laura Donovan, and Chibuzo Oguoma for their inputs in the draft manuscript. We appreciate all members of the state project team, especially Nana Ibrahim, Paul Ochogbu, Abdulrahman Ahmed and all the survey supervisors, data collectors and drivers for their valuable work in ensuring that the data were properly collected and processed. We also thank everyone else, not mentioned above, who supported the fieldwork and express our appreciation to the community drug distributors and health facility workers, who support SMC delivery to eligible children in communities and participated in this study.

\section{Abbreviations}

AQ Amodiaquine

CDD Community drug distributor

CHW Community health worker

$\mathrm{Cl}$

Confidence interval

DOT Directly observed therapy

FGD Focus group discussion

KII Key informant interview

LGA Local government area

MC Malaria Consortium

NMEP National Malaria Elimination Programme

SMC Seasonal malaria chemoprevention

SP Sulfadoxine-pyrimethamine

SPAQ Sulfadoxine-pyrimethamine and amodiaquine 
UNICEF United Nations Children Emergency Fund

VAS Vitamin A supplementation

WDC Ward development committees

WHO World Health Organisation

\section{References}

1. Ritchie H, Reay DS and Higgins P. Quantifying, projecting, and addressing India's Hidden Hunger. Front. Sustain. Food Syst. 2018; 2:11. doi: 10.3389/sufs.2018.00011.

2. Bhutta ZA, Salam RA, Das JK. Meeting the challenges of micronutrient malnutrition in the developing world. British Medical Bulletin. 2013; 106(1): 7-17.

3. Aghaji, A.E., Duke, R. \& Aghaji, U.C.W. Inequitable coverage of vitamin A supplementation in Nigeria and implications for childhood blindness. BMC Public Health 19, 282 (2019). https://doi.org/10.1186/s12889-019-6413-1.

4. Ekweagwu $E$, Agwu AE, Madukwe E. The role of micronutrients in child health: A review of the literature. Afr J Biotechnol 2008; 7: 3804-10.

5. Sommer A, Tarwotjo I, Hussaini G, Susanto D. Increased mortality in children with mild vitamin A deficiency. Lancet. 1983 Sep 10;2(8350):585-8. doi: 10.1016/s0140-6736(83)90677-3. PMID: 6136744.

6. Imdad A, Herzer K, Mayo-Wilson E, Yakoob MY, Bhutta ZA. Vitamin A supplementation for preventing morbidity and mortality in children from 6 months to 5 years of age. Cochrane Database of Systematic Reviews 2010; 8(12). Available from: https://pubmed.ncbi.nlm.nih.gov/21154399 (Accessed 23 ${ }^{\text {rd }}$ December 2020)

7. Kassa G, Mesfin A, Gebremedhin S. Uptake of routine vitamin A supplementation for children in Humbo district, southern Ethiopia: community-based cross-sectional study. BMC Public Health 2020 Oct 2; 20(1): 1500. doi: 10.1186/s12889-020-09617-1. PMID: 33008352; PMCID: PMC7532605.

8. Guideline: Vitamin A Supplementation in Infants and Children 6-59 Months of Age. Geneva: World Health Organization; 2011. Recommendation. Available from: https://www.ncbi.nlm.nih.gov/books/NBK185160 (Accessed 23 $3^{\text {rd }}$ December 2020)

9. Dalmiya N, Palmer A. Vitamin A supplementation: a decade of progress: UNICEF; 2007.

10. National Population Commission (NPC) [Nigeria] and ICF 2019. Nigeria demographic and health survey 2018. Abuja, Nigeria and Rockville, Maryland, USA: NPC and ICF.

11. UNICEF. Evaluation of the maternal, newborn and child health week in Nigeria 2016. Available from: https://www.unicef.org/nigeria/sites/unicef.org.nigeria/files/2018-09/Nigeria-evaluation-ofmaternal-newborn-and-child-health-week_0.pdf. (Accessed $23^{\text {rd }}$ December 2020) 
12. National Bureau of Statistics of Nigeria. National Nutrition and Health Survey 2018. Report on the nutrition and health situation of Nigeria. UNICEF; 2018. Available

from: https://www.unicef.org/nigeria/media/2181/file/Nigeria-NNHS-2018.pdf_(Accessed 23 ${ }^{\text {rd }}$ December 2020)

1. Kisinza WN, Kisoka WJ, Mutalemwa PP, Njau J, Tenu F, Nkya T, et al. Community directed interventions for malaria, tuberculosis and vitamin $\mathrm{A}$ in onchocerciasis endemic districts of Tanzania. Tanzan J Health Res. 2008 Oct;10(4):232-9.

2. The CDI Study Group. Community-directed interventions for priority health problems in Africa: results of a multi-country study. Bull World Health Organ. $2010 \mathrm{Jul}$ 1;88(7): 509-18.

3. Linehan M, Hanson C, Weaver A, Baker M, Kabore A, Zoerhoff KL, et al. Integrated implementation of programs targeting neglected tropical diseases through preventive chemotherapy: proving the feasibility at national scale. Am J Trop Med Hyg. 2011; 84: 5-14.

4. Tine RC, Ndiaye P, Ndour CT, Faye B, Ndiaye JL, Sylla KN, et al. Acceptability by community health workers in Senegal of combining community case management of malaria and seasonal malaria chemoprevention. Malar J. 2013; 12: 467.

5. WHO Policy Recommendation: Seasonal Malaria Chemoprevention (SMC) for Plasmodium falciparum malaria control in highly seasonal transmission areas of the Sahel sub-region in Africa (2012). Global Malaria Programme, World Health Organization.

6. Malaria Consortium. 2019 coverage report: seasonal malaria chemoprevention in Burkina Faso, Chad and Nigeria. April 2020. Available from Malaria_Consortium_Coverage_report_2019.pdf (givewell.org) (Accessed 23 $3^{\text {rd }}$ December, 2020)

7. SMC and vaccination in the north of Mali. Available at: https://www.msf.org.za/stories-news/videophotos/photo-gallery/smc-and-vaccination-north-mali (Accessed 5th February, 2021)

8. Ward A, Guillot A, Nepomnyashchiy LE, Graves JC et al. Seasonal malaria chemoprevention packaged with malnutrition prevention in northern Nigeria: A pragmatic trial (SMAMP study) with nested case-control. PLoS One 2019 Jan 25; 14(1): e0210692.

9. Oliver M, Geniets A, Winters N, Rega I, Mbae SM. What do community health workers have to say about their work, and how can this inform improved programme design? A case study with CHWs within Kenya. Glob Health Action. 2015 May 22; 8: 27168.

10. Smith S, Deveridge A, Berman J, Negin J, Mwambene N, Chingaipe E, Puchalski Ritchie LM, Martiniuk A. Task-shifting and prioritization: a situational analysis examining the role and experiences of
community health workers in Malawi. Hum Resour Health. 2014 May 2; 12: 24.

11. Federal Government of Nigeria. Extraordinary Federal Government of Nigeria Official Gazette No 4, Vol 94. Page B 47-53. Legal Notice on Publication of the 2006 Census Report. Lagos: Federal Government of Nigeria; 2007.

12. Jeph Herrin, 2002. "CLTEST: Stata modules for performing cluster-adjusted chi-square and ttests," Statistical Software Components S424901, Boston College Department of Economics, revised 
03 Feb 2012.

13. Bowen DJ, Kreuter M, Spring B, Cofta-Woerpel L, Linnan L, Weiner D, Bakken S, Kaplan CP, Squiers L, Fabrizio C, Fernandez M. How we design feasibility studies. Am J Prev Med. 2009 May;36(5): $452-7$.

14. Sekhon M, Cartwright M, Francis JJ. Acceptability of healthcare interventions: an overview of reviews and development of a theoretical framework. BMC Health Serv Res. 2017 Jan 26; 17(1): 88.

15. Coldiron, M.E., Von Seidlein, L. \& Grais, R.F. Seasonal malaria chemoprevention: successes and missed opportunities. Malar J 2017; 16: 481. https://doi.org/10.1186/s12936-017-2132-1.

16. Kombate, G., Guiella, G., Baya, B. et al. Analysis of the quality of seasonal malaria chemoprevention provided by community health Workers in Boulsa health district, Burkina Faso. BMC Health Serv Res 19, 472 (2019). https://doi.org/10.1186/s12913-019-4299-3

17. Smith, S., Dev.eridge, A., Berman, J. et al. Task-shifting and prioritization: a situational analysis examining the role and experiences of community health workers in Malawi. Hum Resour Health 2014; $12,24$.

18. Koblinsky MA, Brechin SJ, Clark SD, Hasan MY. Helping managers to manage: work schedules of field-workers in rural Bangladesh. Stud Fam Plann. 1989 Jul-Aug;20(4):225-34. PMID: 2772996.

19. Alvarez Morán JL, Alé FGB, Rogers E, Guerrero S. Quality of care for treatment of uncomplicated severe acute malnutrition delivered by community health workers in a rural area of Mali. Matern Child Nutr. 2018 Jan;14(1): e12449. doi: 10.1111/mcn.12449. Epub 2017 Apr 5. PMID: 28378463;

20. López-Ejeda N, Charle Cuellar P, Vargas A, Guerrero S. Can community health workers manage uncomplicated severe acute malnutrition? A review of operational experiences in delivering severe acute malnutrition treatment through community health platforms. Matern Child Nutr. 2019 Apr;15(2): e12719. doi: 10.1111/mcn.12719. Epub 2018 Nov 8.

21. Simmons R, Koenig MA, Huque AA. Maternal-child health and family planning: user perspectives and service constraints in rural Bangladesh. Studies in Family Planning 1990; 21:187-96.

22. Glenton C, Scheel IB, Pradhan S, Lewin S, Hodgins S, Shrestha V. The female community health volunteer programme in Nepal: Decision makers' perceptions of volunteerism, payment and other incentives. Social Science and Medicine 2010; 70(12):1920-7.

23. Oliver M, Geniets A, Winters N, Rega I, Mbae SM. What do community health workers have to say about their work, and how can this inform improved programme design? A case study with CHWs within Kenya. Glob Health Action 2015 May 22; 8: 27168.

24. Malaria Consortium. Co-implementing vitamin A supplementation with seasonal malaria chemoprevention: a pilot implementation study in Sokoto state, Nigeria. Research brief; 2020. Available from www.malariaconsortium.org (Accessed 20 th December, 2020)

25. Koenker, H., Keating, J., Alilio, M., Acosta A., Lynch M., Nafo-Traore F. Strategic roles for behaviour change communication in a changing malaria landscape. Malar J 2014;

13: 1. https://doi.org/10.1186/1475-2875-13-1. 
26. Greenspan, J.A., McMahon, S.A., Chebet, J.J. et al. Sources of community health worker motivation: a qualitative study in Morogoro Region, Tanzania. Hum Resour Health 2013; 11,

52. https://doi.org/10.1186/1478-4491-11-52

27. WHO 2016: Global coordination mechanism on the prevention and control of noncommunicable diseases: Interim report. Available at: https://www.who.int/global-coordination-mechanism/workinggroups/GCM (Accessed 23rd April 2021)

28. Mubyazi GM, Mushi A, Kamugisha M, Massaga J, Mdira KY, Segeja M, Njunwa KJ. Community views on health sector reform and their participation in health priority setting: case of Lushoto and Muheza districts, Tanzania. J Public Health 2007; 29(2): 147-56.

29. Masanja H, Schellenberg JA, Mshinda HM, Shekar M, Mugyabuso JKL, Ndossi GD, et al. Vitamin A supplementation in Tanzania: The impact of a change in programmatic delivery strategy on coverage. BMC Health Services Research 2006; 6: 142. Available from: https://doi.org/10.1186/14726963-6-142.

30. Boselli G, Yajima A, Aratchige PE, Feldon KE, Xeuatvongsa A, Phounphenghak K, et al. Integration of deworming into an existing immunisation and vitamin A supplementation campaign is a highly effective approach to maximise health benefits with minimal cost in Lao PDR. International Health 2011;3(4): 240-5.

31. Clohossey PC, Katcher HI, Mogonchi GO, Nyagoha N, Isidro MC, Kikechi E, Okoth EE, Blankenship JL. Coverage of vitamin A supplementation and deworming during Malezi Bora in Kenya. J Epidemiol Glob Health. 2014 Sep; 4(3): 169-76.

32. Adesoro A. Adapting SMC in Nigeria during the COVID-19 pandemic: Enhancing safety and minimising risk. A webinar presentation. Available at: https://www.psi.org/wpcontent/uploads/2020/10/200929_Malaria-Consortium_SMC-Webinar-Presentation_FINAL-en.pdf

\section{Figures}



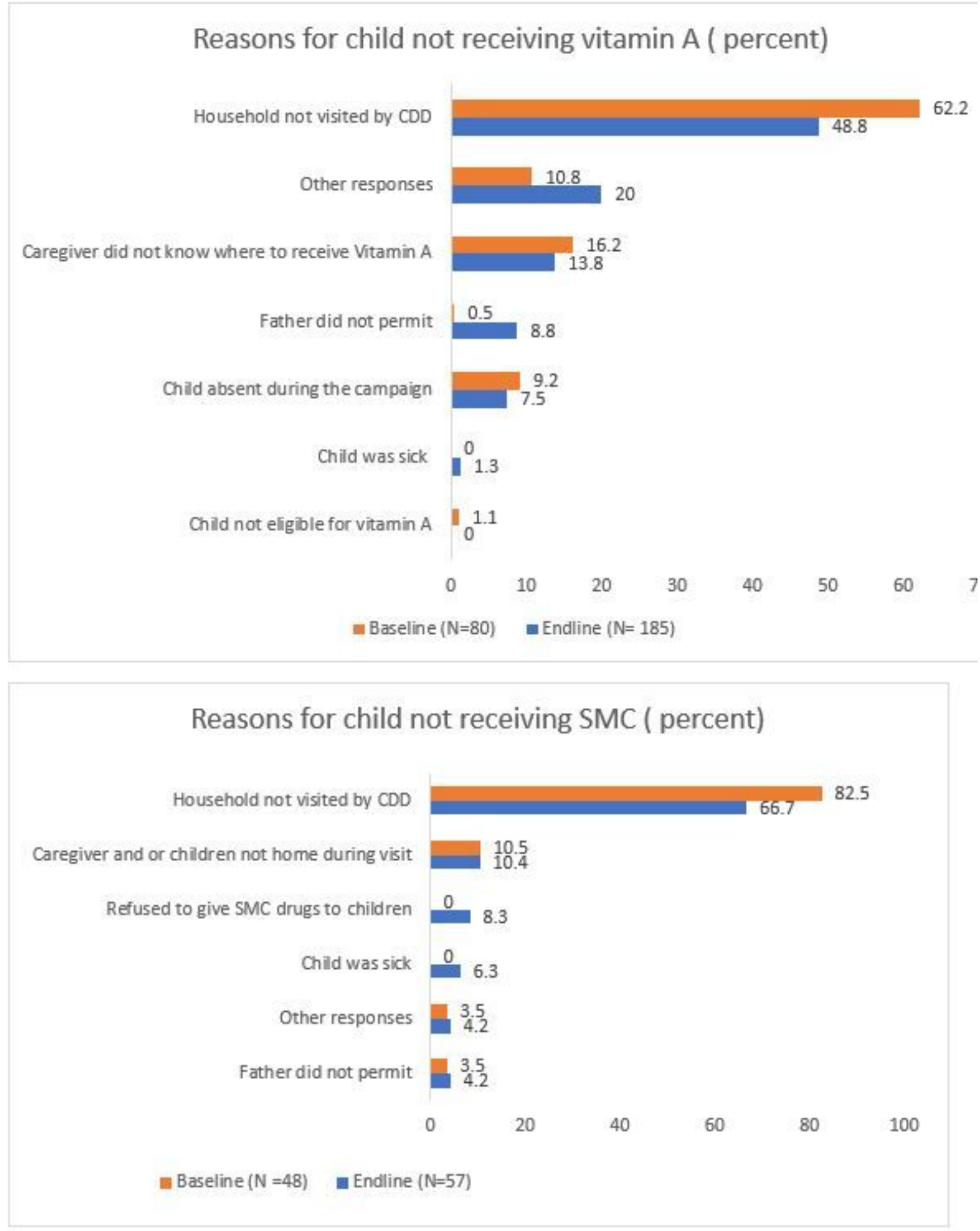

\section{Figure 1}

Reasons for child not receiving vitamin A (percent) 


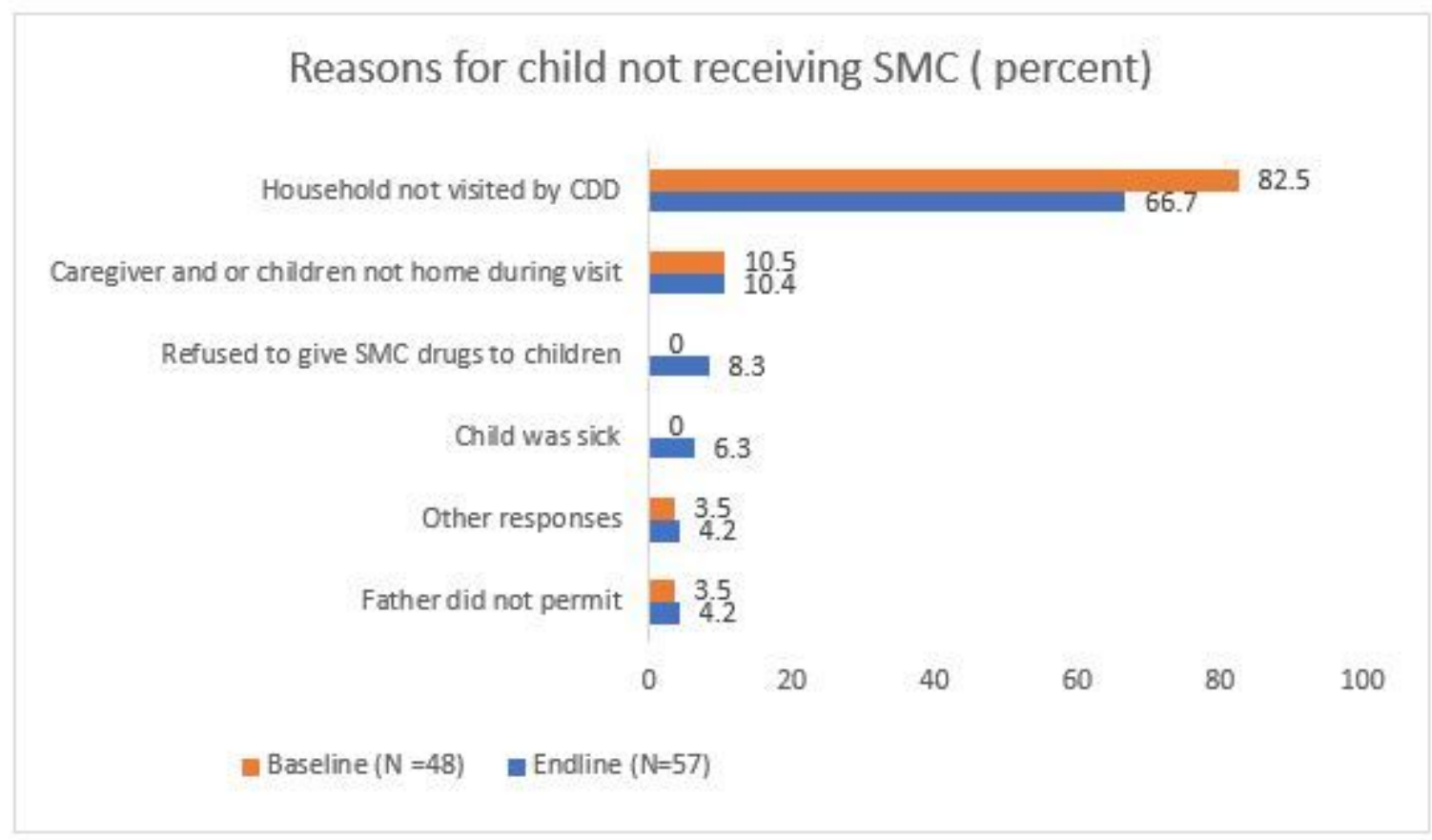

Figure 2

Reasons for child not receiving SMC 